\title{
Contemporary Values of the Thoughts of Moral Education in the Traditional Family Instructions
}

\author{
Yufeng Jiang \\ School of Marxism, Zhejiang University \\ Hangzhou, China 310028
}

\begin{abstract}
China is a country where people attach great importance to family education. Under this background, the traditional family instructions as the literature of family education have produced and survived today. Being an organic component of the traditional culture, the traditional family instructions entail extremely ample thoughts of moral education, which have played a significant role in enhancing individual morality, cultivating family virtues and social custom and replenishing the moral education of schools.
\end{abstract}

Keywords - traditional family instructions; thoughts of moral education; contemporary values

\section{INTRODUCTION}

China has been a country with an ancient civilization and a glorious history of five thousand years and been worldrenowned for emphasizing family education. Family instructions are the crystal of the wisdom in people's family education and contain abundant thoughts of moral education. The thoughts have very important values on propelling the socialism spiritual civilization construction.

\section{THE VALUE OF ENHANCING INDIVIDUAL MORALITY}

Firstly, it is beneficial to firm the moral belief. "Morality originates from the needs in the social life of human being, but it has survived and been inherited in the way of belief, in the process of its own development. Without the support of belief, the morality will no exist in reality, because the basic feature of morality is self-discipline, which is not compulsory but willing." In the process of moral education on younger generations, the traditional family instructions emphasize establishing a steadfast moral belief and fuel the moral improvement via the power of belief. For example, Gao Panlong enlightens his descendants, "in this world, we must consider how a people should behave, which is the priority among priorities. Other things are not as important as it". He especially emphasizes the consideration of a person's behaviors, which is superior to everything else. Xue Xuan, an ideologist of the Ming Dynasty, addresses, "the thing that distinguishes people from animals is Lun $\mathrm{Li}$ (namely ethic). What is Lun? It is the relations between father and son, between the monarch and his subjects, between husband and wife, between older and younger as well as between friends. What is Li? It means the affection between father and son, the justice between the monarch and his subjects, the attention paid to the proper and different roles of husband and wife, the respect for seniority and the faithfulness between friends. Only when we explicitly know the ethics and follow it can we be called a person. If people ignore ethics, their behaviors are the same as that of animals, even though they are people in the eyes of others". He regards morality as the fundamental of person in a real sense. These admonishments will benefit the reinforcement of moral belief and better guide the moral practice.

Secondly, it is beneficial to hone moral will. The traditional family instructions put a high value on honing the moral will of descendants. Once we establish the moral belief, we must persevere and steadfastly practice moral belief Instead of establishing while in high spirits and changing while meeting resistance, we must make morality consistent and stable. Zuo Zongtang preaches to his descendants, "I am worried you do not establish ambition, especially your ambition is infirm. When hearing good words or a good thing, you also excite and admire and say I want to behave like him at that time. However, after a few days, the thought disappears somehow. Is it because your ambition is infirm or you fail to establish ambition?" Zeng Guofan observes, "Having perseverance is the first virtue in our life. No matter you are old or young, no matter things are difficult or easy, if we persevere, naturally it will like planting trees and raising livestock. We see them grow up and mature but fail to perceive that." The thoughts have had a strong reference function on strengthening moral practice and honing moral will today.

Thirdly, it is beneficial to improve moral ability. As the norm for people to act, morality embodies "what ought to be". However, "what ought to be" will not realize automatically. The process from "what ought to be" to "become reality" requires people to give their subjective initiative into full play and practice proactively. In this process, the moral ability appears to be particularly important. Those who give family instructions lay particular emphasis on cultivating different moral ability. Cai Yong advocates "embellishing the heart" and thinks "The heart resembles the head and the face, which need careful embellishment. The face will be tarnished by dirt once we do not embellish it; we will have wicked thoughts once we do not cultivate our mind." 1 Wang Fuzhi advocates "being free from vulgarity" and proposes "at the beginning of establishing ambition, we must first abolish bad habits. Bad habits will influence people and make us drunk without the function of wine. It approaches without casting a shadow and leave without leaving a trace". 2 Zeng Guofan advocates reading and thinks "it is difficult to change the temperament of 
people originally because it is inborn. And only by reading can we change the temperament". 3 The emphases are different, but all of them have a relatively strong reference value for the improvement of the moral ability of people.

\section{The Value of CUltivating Family ViRTUES}

Firstly, it is beneficial to create a harmonious family. Family virtues are the standard of the behavior of family members in the family. The Chinese nation has always paid attention to the family, family tradition and family education and advocated that we must regard harmony as the priority among priorities in regulating a family and emphasized a happy family means wealth. Deeply affected by the thought, the traditional family instructions have attached great importance to the harmony of family relationship. In regard to the morality of husband and wife, it advocates the husband should be gentle and righteous and the wife should be mild and obedient and they must mutually respect and love; in regard to the morality of parents, the parents must raise children, love them when raising, teach them when loving; in regard to the morality of children, children must support parents, give presents to parents and be filial to parents; brothers must live together and share properties, have friendliness and respect and live in harmony. These moral rules enable different family members to explicitly know the code of conduct, moral requirements and obligations and responsibilities that correspond to their identity, so that family members will have rules and laws to follow in family life. Meanwhile, it has provided the guarantee of moral rules for the creation of a harmonious family relationship.

Secondly, it is beneficial to the formation of the ethos of respecting the old. Nowadays, China has gradually become an aging society. It is estimated that the aging population will reach 250 million by 2020; the aging population will account for about 35 percent of the total population by 2050 . China is still in the primary stage of socialism and the overall level of the social and economic development is not high. Furthermore, it is difficult for the social security level to deal with the tide of an aging society. The traditional family supporting pattern that children support the old will be still the mainstream. The traditional family instructions have put a particular emphasis on supporting parents. In the Instructions of the Lin Family in the Ming Dynasty, it points out, "no matter rich or poor, children must first support parents while serving them. The rich can prepare and provide delicacies and the poor can provide beans and water for parents, attend upon and please parents. They do according to their abilities. Children must inherit the ambition of parents and support parents with a kind and pleasant countenance and euphemistic words and should neither violate their wish nor make them worried". In the Instructions of the Bai Family, it proposes, "We must support parents with filial piety. Filial piety contains many aspects and emphasizes consideration. We must always obey the order of parents. When the parents are alive, we must do our utmost to serve the parents. If they have passed away, we must achieve the dream of parents". Proactively carrying forward the idea of serving and supporting parents in the traditional family instructions will have a relatively strong practical significance on forming the ethos of respecting and loving the old in a family and coping with difficulties in the aging society.

Thirdly, it is beneficial to create a harmonious neighborly relation. As the old saying goes, a good neighbor is better than a brother far off. The harmonious neighborly relation is of vital importance for the happiness of a family. In today's society, with the acceleration of people's pace of life and the change of our living pattern, people have easily neglected the communication with neighbors. The phenomenon that the neighborly relation is cool has prevailed. People of the same clan in the ancient society of China often live close to each other. The situation that "People in a village share the same family name" is quite universal. Their houses have independent structure but are close to each other. The communication between neighbors is frequent and it is popular that neighbors help each other. Therefore, the traditional family instructions pay special attention to the establishment of the neighborly relation. In the Norms of the Yuan Family, it observes, "we cannot live without neighbors. Without neighbors, nobody will aid and support once fire disaster appears. If there are no brooks near our house, there must be ponds or wells. Without them, we cannot fetch water to put out a fire once fire disaster appears. Besides, at ordinary times, we must show kindness to neighbors. Once there was a scholarofficial who bullied neighbor by virtue of his official post and power. One day, his enemies killed his family members and burned his houses. His neighbors warned each other, 'If we fight the fire, after the fire is put out, he will not only deny our contribution but also accuse us of stealing his properties, then the deadline of lawsuit is unknown. If we do not fight the fire, we will only suffer from one-hundred times of flogging with a stick. 'Neighbors would rather suffer from flogging with a stick and see his mansion burning to ashes than put out the fire. Nothing is left after that. It is the result of his ruthlessness at ordinary times". In the Family Instructions of Zeng Guofan, it emphasizes, "Li Shenfu's mother once said, 'people treat distant relatives with money and wine and call on neighbors when there are fire disasters and robbery', in order to warn rich families that they should not only respect distant relatives but slight neighbors. We just move to Futuo and should not slight neighbors but treat them with wine and food and be polite and respectful. If Jian Siye is not in my home, you can also invite another person to treat the guests. Except for not meddling in others' business and helping others in the lawsuit, you should not be mean in making things convenient for others." Although the two family instructions regarding good-neighborliness aims at the aid and support of neighbors when disasters appear, but the thoughts of "comforting and compensating neighbors", "people should treat neighbors with wine and food and be polite and respectful" mentioned in it have a relatively strong reference value on establishing a harmonious neighborly relation in the contemporary era.

\section{The Value of Cultivating Social Custom}

Firstly, it is beneficial to form the ethos of patriotism. In the eyes of those who give traditional family instructions, family and country are highly consistent. One who can serve and support parents with filial piety will be loyal to his country. Therefore, only by cultivating the good moral characters of the 
younger generation from their childhood can we guarantee the children will form the character of repaying the country with supreme loyalty after they grow up. In particular, when the interests between individual and the country are inconsistent, we must give preference to the national interest and sacrifice personal interests even life to safeguard national interests. When Chen Yuangui, a famous general in the Southern Song Dynasty who defends against the Yuan Dynasty, guards Linjiang, he leaves the admonishment when the situation is critical, "rather than dieing of hunger, disease and the persecution of robbers, we should die of defending the territory of our country, which is glorious and great". Shen Lian, an official loyal to his sovereign in the Ming Dynasty takes Fan Zhongyan, a famous official of the Northern Song Dynasty, as an example and enlightens his sons to be on intimate terms with faithful and righteous persons and alienate vile persons. When the nation is in danger and disaster, we should shoulder the responsibility and make a difference. Fang Shengdong, a righteous man in the late Qing Dynasty, writes to his father on the day before Guangzhou Uprising and says frankly, "In this world, although a man cannot make the nation strong via making contribution to it, it is a great pleasure to make the compatriot enjoy a happy life. In addition, sacrificing for the nation is also deserved... When your grandson Xu grows up, I expect you to teach him patriotism". 4 These are good examples for education in patriotism and should become precious resources to cultivate the patriotism of contemporary people and arouse them to untiringly struggle in order to realize the Chinese Dream of the great rejuvenation of the Chinese nation.

Secondly, it is beneficial to form the ethos of cherishing posts and devoting wholeheartedly to work. Dedication to work is an important content of the socialist core values. The cultivation of the socialist core values must base on the traditional culture. As an organic component of the traditional culture, family instructions attach great importance to the education of children in dedication to work. In the ancient society, reading and writing is only the rights of people from upper class. The masses seldom have the opportunity to learn cultural knowledge. Therefore, most of the existing family instructions are written by government officials from aristocratic families. The professional ethics of family instructions intensively reflect the official morality. Lyu Benzhong warns his descendants, "The way of being an official only contains three aspects, namely be incorruptible, be cautious and be industrious. Those who know the three aspects will conduct themselves properly." Jia Changchao says, "Incorruptibility is the priority among priorities in being an official. We must hear a case in detail and be charitable in judgment." In the Norms of Zheng Family, it advocates, "once being an official, you must be honest in performing official duties and diligent in administration and shall not act wantonly to bring disgrace to the family discipline." The above family instructions contribute to the inheritance of the culture of an honest and clean government in the ancient times and the creation of a clean and upright style of work and a fine family tradition among the leading cadres. Furthermore, it will propel the improvement of the professional ethics of contemporary officials and drive the enhancement of the overall level of professional ethics in the society as well as form the ethos of cherishing posts and devoting wholeheartedly to work.

Thirdly, it contributes to forming the ethos of helping each other. Being forward to help others has been always one of the important contents of the traditional family instructions. Liu Yuan would rather be frugal and help the poor with spare money. He warns his descents, "We have food to eat and clothes to wear. Those without clothes and food and being hungry and cold are miserable. You should be frugal and help the poor with spare money. You should not be mean to relatives of your brothers and others. The ancients say that the deities in the world will sympathize with you if you take pity on the poor. The situation that your descendants become hungry and cold because of helping the poor will never happen." Wang Shijin teaches his descendants to help the vulnerable groups in the society, "There are four obligations, namely sympathizing with the young and the weak, showing solicitude for orphans and widows, helping people to cope with an emergency as well as enlightening people in resentment and competition. The young and the weak are easily bullied by others, so you must sympathize with them. Once you have a mercy heart, you will naturally offer help for them everywhere. Even the government attaches importance to those who have no kin and cannot support themselves, letting alone those clansmen whose misfortunes are heard and seen by us? You must sympathize with them. The poor can show solicitude for them with good words and the rich with money and grains, which are good deeds to the doer's credit in the next world. People who have no clothes and food are in straitened circumstances and star-crossed, so you should help them out. When helping others, you should consider others' situation and yours and help if condition allows. It is unnecessary to expect them to pay a debt of gratitude and let others know. It is enough to put my heart and soul into them. People who are in resentment will easily argue and compete with others. They will become ataractic if there is a person to propitiate them. If a person goads them, they will be more excited and angry and most of them will lose themselves. It is the responsibility of the clansman to mediate. The clansman also accumulates merits. The four obligations can be expounded as eleemosynary farmland, eleemosynary barn, eleemosynary school and eleemosynary tomb. Those who shoulder the responsibility of bringing up clansmen and protecting them from becoming destitute and homeless should be called heroes." Similar thoughts have a strong guiding significance on strengthening the consciousness of contemporary citizens in helping others and creating a harmonious society.

\section{The Value of SupPlementing Moral Education IN SCHOOLS}

Firstly, it is conducive to covering the shortage of the moral education of schools. Most of the people who give the traditional family instructions are officials and intellectuals. They are knowledgeable and experienced and successfully realize the importance of morality on the development of a person and a family. Morality can be handed down to more than ten generations to prosper a family, and the followings are farming and reading, poetry and literature. Wealth and rank 
only be handed down to no more than three generations in a family. In order to make the family prosperous, people who give family instructions have paid special attention to cultivating the moral character of their children and regarded the cultivation of a good morality as the primary goal of education. By contrast, in the contemporary era, under the general background, the society, parents and education authorities evaluate schools only according to the test scores and enrolment rate. Under the general orientation of the eleven-plus, when all sectors of society is paying high attention to scores and enrolment rate, schools always put intellectual education in the core status of education. Moral education has always in the embarrassing situation that it is important when people mention it, secondary in doing and abandoned by people in a hurry. Most of schools fail to coordinate the relation between moral education and intellectual education, leading to the disordered educational objectives and declinational educational orientation. "The educational orientation that attaches more importance to intelligence than morality, scores than ability has turned children into learning tools and examination machines and influenced the formation of a healthy personality. Many children have shown misbehaviors of being strongly aggressive, lordly and imperious, self-centered, self-concern, narrow and stubborn and capricious. These children are huge hidden troubles for individuals, family, society and even the whole nation." "Family is the cradle of education and the first school of children. Parents are the first teachers of children, as well as long-term teachers even life-time teachers." Children receive education given by their families. The thoughts, morality and character even the living habits of parents will have imperceptible influence on children, then forming the unique spiritual identity of a family and the spiritual core of it. Family education involves every aspect, but the most important is the moral education. The attention paid by the traditional family instructions to moral education and a series of admonishments undoubtedly have provided an effective reference for the moral education of families to cover the shortage of the moral education of schools.

Secondly, it is beneficial to expanding the methods of moral education. In general, the moral education of schools at present adopts the pattern of subject and object education. In the process of moral education, schools serve as the subject of education and students as the object of education. The subject infuses moral rules into the object in external form. The educational method has been intensively goal-oriented and compulsory, in order to shape and reform the ideology and behavioral habits of the educated into the pattern required by the society. The limitedness of the educational method is distinctly evident. Although it can provide the educated with the scheme of the future moral cognition, it is only remembered by students as knowledge instead of becoming an organic component of the internal morality of students. "The largest weakness is that it ignores the individuality, creativity and subjective initiative of a person and has the suspicion of authoritarian and compulsory infusion. The method 'I teach and you listen' 'I hit and you obey' has little tangible impact on the behaviors of students in the specific moral situation. "We must soberly realize moral education must immerse into our life, relate to life, respect the individual difference of people, value moral practice and play a role of an example. As mentioned above, in terms of the methods of moral education, the traditional family instructions advocate parents must make an example, emphasize differential treatment in education and the coexistence of strictness and love as well as propose the example demonstration. Therefore, it will make for expanding the methods for the moral education of schools and achieve the goal of crystallizing moral education of schools.

\section{CONCLUSION}

At present, China is in the period of social transition, with a brilliant and varied ideological trends and diversified values. Under this background, money worship and hedonism have gradually risen. When pursuing material interests, people often neglect the improvement of their spiritual realm and moral quality. Moral abnormality in society appears frequently and moral decline has been severe. Critically absorbing the thoughts of moral education in the traditional family instructions will be conducive to optimizing family traditions, correcting folk custom and purifying the general mood of society.

\section{REFERENCES}

[1] Chen Hongmou. Five Kinds of Remaining Rules [M], Beijing: ThreadBinding Books Publishing House, 2015: 93

[2] Wang Jingcheng. Home Letters of Celebrities from Past Dynasties of China [M], Beijing: International Culture Publishing House, 2009: 391

[3] Wei Shuting. The Traditional Family Instructions [M], Hefei: Mount Huangshan Bookshop, 2012: 101

[4] Lu Zhengyan. Family Instructions from Past Dynasties of China [M], Shanghai: Xuelin Publishing House, 2004: 47 